\title{
The crosstalk between IncRNA and microRNA in cancer metastasis: orchestrating the epithelial-mesenchymal plasticity
}

\author{
Ming-xin Cao ${ }^{1,2}$, Ya-ping Jiang ${ }^{3}$, Ya-ling Tang ${ }^{1,4}$ and Xin-hua Liang ${ }^{1,2}$ \\ 1 State Key Laboratory of Oral Diseases, West China Hospital of Stomatology (Sichuan University), Chengdu Sichuan, \\ People's Republic of China \\ 2 Department of Oral and Maxillofacial Surgery, West China Hospital of Stomatology (Sichuan University), Chengdu Sichuan, \\ People's Republic of China \\ ${ }^{3}$ Department of Implant, The Affiliated Hospital of Qingdao University, Qingdao,Shandong, People's Republic of China \\ ${ }^{4}$ Department of Oral Pathology, West China Hospital of Stomatology (Sichuan University), Chengdu Sichuan, People's \\ Republic of China \\ Correspondence to: Xin-hua Liang, email: 1xh88866@scu.edu.cn
}

Ya-ling Tang, email: tangyaling@scu.edu.cn

Keywords: IncRNA, microRNA, epithelial-mesenchymal plasticity, cancer metastasis

Received: October 15,2016 Accepted: December 12,2016 Published: December 15, 2016

\section{ABSTRACT}

\begin{abstract}
Noncoding RNAs (ncRNAs) have been demonstrated to closely associate with gene regulation and encompass the well-known microRNAs (miRNAs), as well as the most recently acknowledged long noncoding RNAs (IncRNAs). Current evidence indicates that IncRNAs can interact with miRNAs and these interactions play crucial roles in cancer metastasis, through regulating critical events especially the epithelialmesenchymal transition (EMT). This review summarizes the types of IncRNAmiRNA crosstalk identified to-date and discusses their influence on the epithelialmesenchymal plasticity and clinical metastatic implication.
\end{abstract}

\section{INTRODUCTION}

Cancer stems from the introduction of genetic mutations in normal cells to the biochemical changes of chromatin, signaling pathways and cell biological processes $[1,2]$. The final manifestation of this disease usually comes to metastasis, responsible for more than $90 \%$ of cancer-associated mortality [3]. Many experimental and clinical studies have been tried to underlie the biology of this metastatic cascade. And there comes epithelial-mesenchymal plasticity, involving "changing faces" between epithelial cells and mesenchymal cells $[4,5]$. Epithelial cells can undergo multiple biochemical changes to get a mesenchymal cell phenotype (EMT), and its reversible process, mesenchymal-epithelial transition (MET), can revert the mesenchymal cells back to epithelial cells $[6,7]$. This bidirectional process contributes to the invasionmetastasis cascade from local invasion, then intravasation into nearby blood and lymphatic vessels, transition through the systems, extravasation into the parenchyma of distant tissues, finally colonization at particular distant sites $[8,9]$ (Figure 1). Given that emerging evidence has supported that de-differentiation of cancer cells through EMT with enhanced motility and dissemination, and re-differentiation through MET with colonization are critical in the course of multi-stage tumor progression, targeting EMT plasticity is thought to be a promising way to treat metastasis $[10,11]$. Therefore, understanding the molecular mechanisms of governing EMT/MET in cancer metastasis cascade is vitally important.

Noncoding RNAs (ncRNAs), though do not encode proteins, contain genetic information or have function in the biological process of cells. NcRNAs include structural RNAs such as rRNAs and tRNAs involved in mRNA translation, small nuclear RNAs (snRNAs) involved in splicing, and regulatory RNAs such as microRNAs (miRNAs) and long noncoding RNAs (lncRNAs) [12]. All of them have important roles in regulating gene expression in development, physiology and pathology. Among these ncRNAs, the well-known miRNAs ( 22 nts), which are considered as central post-transcriptional gene regulators through their complementarity with the target mRNA sequences [13], and lncRNAs ( $>200$ nts), known as the "transcriptional noise", which exhibit numerous functions in normal and abnormal tissues, are developing gradually 
$[14,15]$. Recently, there is an interesting cross-regulation between lncRNAs and miRNAs, and the emerging evidence provides that this crosstalk has a great impact on the mechanisms of cancer metastasis [16]. In this review, we summarized miRNAs' and lncRNAs' control of EMT/MET, emphasized the influence of IncRNAmiRNA crosstalk in this multi-step process of human tumor progression, and harnessed this knowledge for translational medicine.

\section{KEY REGULATORS OF EMT/MET}

Key regulators of EMT were categorized into three groups, including EMT effectors, EMT core regulators, and EMT inducers [1]. EMT effectors usually are proteins, which demarcate the epithelial or mesenchymal identity of a cell such as E-cadherin, $\alpha$-catenin, $\gamma$-catenin and vimentin or promote cell migration and invasion during EMT like fibronectin. Decreased E-cadherin, $\alpha$-catenin, $\gamma$-catenin and increased vimentin, fibronectin are consistent markers during EMT. Among them, E-cadherin is regarded as the leading one [17]. EMT core regulators consist of transcription factors, including Snail1 and Snail2, Zeb1 and Zeb2, Twist1 and Twist2, and the newly discovered paired-related homeobox transcription factor 1 (Prrx1)
$[5,17-20]$, which dynamically modulate EMT mainly by regulating the expression of E-cadherin [21, 22]. EMT inducers are many signaling pathways, including TGF- $\beta$, Wnt, Notch and growth factor receptor signaling cascades $[23,24]$. Most notably, the TGF- $\beta$ pathway appears to be a primary inducer of EMT $[6,25,26]$. Besides, tumor inflammation and hypoxia microenvironment also play fundamental roles in promoting EMT [27, 28].

Conversely, MET is characterized by decreased expression of mesenchymal markers, such as N-cadherin and vimentin, and concomitant increased expression of epithelial markers, such as E-cadherin and CK-19 [6]. Recent studies have pointed out that BMPs, as multifunctional cytokines of the TGF- $\beta$ superfamily, have been involved in mediating MET programs and boosting metastatic outgrowth by antagonizing the activities of TGF- $\beta[7]$.

Recently, EMT is reported to be regulated by posttranscription factors, such as miRNAs and lncRNAs, which exert their influence by regulating effectors, transcription factors and signaling pathways [29, 30]. The underlying molecular mechanisms of EMT/MET has refined our understanding of how this phenomenon may be affected by post-transcription factors like miRNAs and lncRNAs.

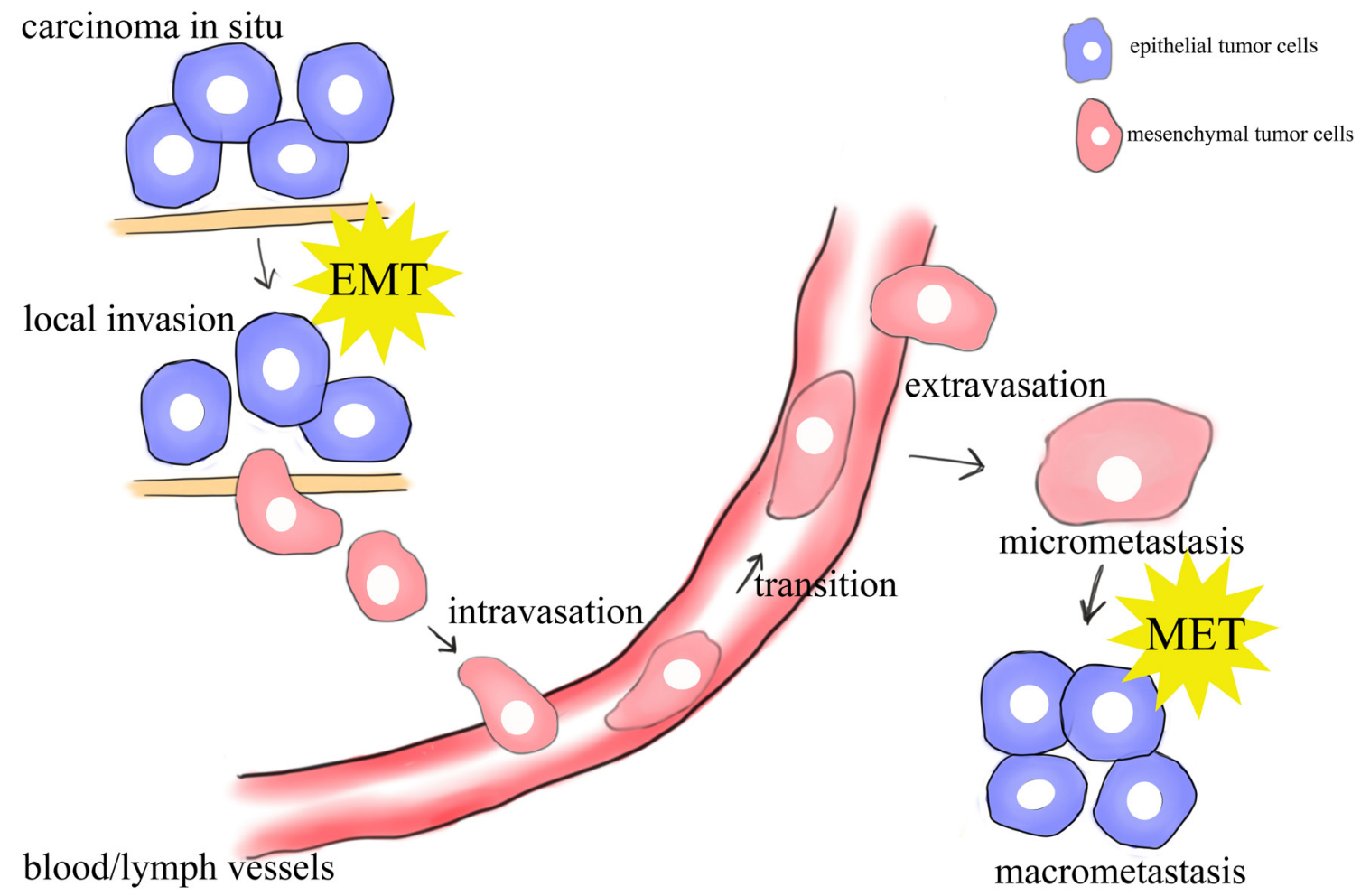

Figure 1: schematic mode of the sites of EMT/MET in the metastasis of cancer. Epithelial cells undergo epigenetic changes and genetic alterations to become carcinoma in situ. Further alterations can induce local invasion of tumor cells, possibly through an EMT. The cells can intravasate into nearby blood and lymphatic vessels, be transported through the systems, and extravasate into the parenchyma of distant tissues. These cells may either be solitary or form a secondary tumor through a MET. 


\section{MICRORNAS' CONTROL OF EPITHELIAL- MESENCHYMAL PLASTICITY}

MiRNAs exert their influences, most of which are repressive, through targeting not only mRNAs, but also DNA and proteins [31]. Given that EMT can be regulated by post-transcription factors, a field of study has emerged requiring more efforts on the miRNAs control of EMT. Recently, a link between miRNAs and EMT has been extensively elucidated, and numerous miRNAs have been discovered to impact the process of EMT [32-35].

\section{EMT-inhibiting miRNAs}

MiR-200 family members, including miR-200a, b, c, miR-141 and miR-429, are the first discovered, and also the most widely studied EMT-related miRNAs [36-
38]. Decreased expressions of them suppress E-cadherin and initiate EMT by targeting transcription factors ZEB1 and ZEB2. Conversely, ectopic expressions of these miRNAs in mesenchymal cells induce MET through downregulating ZEB1/2 levels, and thus increasing E-cadherin and decreasing N-cadherin [39-41]. Given the fact that miR-200 family members inhibit expression of ZEB by binding to highly conserved target sites in their 3'UTRs and ZEB factors in turn repress the genes of miR-200 family members by binding to highly conserved recognition sequences in their promoters, Emerging data have demonstrated that there is a double-negative feedback loop between them. This feedback loop controls EMT/MET process through balanced expression of miR200 family and ZEB factors in cancer microenvironment [42]. Further studies find more evidence about the miR200 family. miR-200c inhibits metastasis of breast cancer by downregulating high mobility group protein

\section{epithelial phenotype}

\section{mesenchymal phenotype}

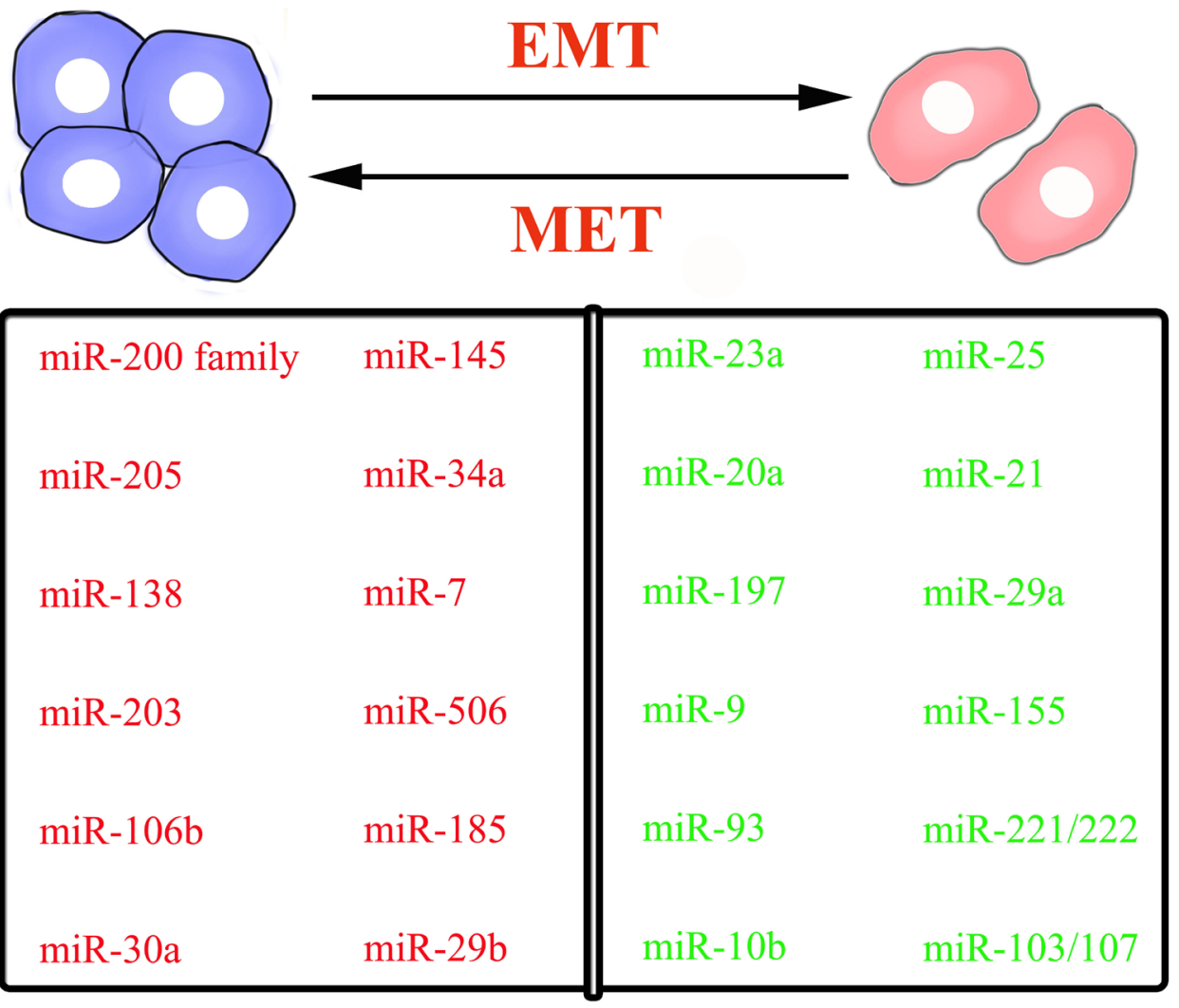

Figure 2: schematic mode of epithelial-mesenchymal plasticity and selected miRNAs important for the epithelial or mesenchymal phenotype. 
Table 1: selected EMT-related IncRNAs showing diverse mechanisms of action

\begin{tabular}{|l|l|l|}
\hline \multicolumn{1}{|c|}{ LncRNA } & \multicolumn{1}{|c|}{ Mechanisms of action } & \multicolumn{1}{c|}{ References } \\
\hline MALAT-1 & $\begin{array}{l}\text { Interacts with suz12 resulting in suppression of E-cadherin } \\
\text { and activation of N-cadherin and fibronectin. Affected by } \\
\text { tumor micro-environment. }\end{array}$ & $\begin{array}{l}\text { Ji et al. [75] } \\
\text { Fan et al. [76] } \\
\text { Kan et al. [80] }\end{array}$ \\
\hline HOTAIR & $\begin{array}{l}|c| \\
\text { Reprograms chromatin state. }\end{array}$ & $\begin{array}{l}\text { Qiu et al. [82] } \\
\text { Ku et al. [83] } \\
\text { Kim et al. [84] }\end{array}$ \\
\hline BANCR & Histone de-acetylation suppresses BANCR to promote EMT. & $\begin{array}{l}\text { Guo et al. [96] } \\
\text { Sun et al. [97] }\end{array}$ \\
\hline H19 & Chromatin modifier. & Matouk et al. [85] \\
\hline Linc00617 & Stimulates EMT via activating the transcription of Sox2. & Li et al. [86] \\
\hline LncRNA-HIT & $\begin{array}{l}\text { Promotes TGF- } 3 \text {-induced EMT via downregulating the levels } \\
\text { of E-cadherin. }\end{array}$ & Richards et al. [98] \\
\hline AOC4P & $\begin{array}{l}\text { Inhibits EMT via binding to vimentin and promoting its } \\
\text { degradation. }\end{array}$ & Wang et al. [87] \\
\hline HULC & Affected by tumor micro-environment. & Matouk et al. [89] \\
\hline LncTCF7 & Affected by tumor micro-environment. & Hamada et al. [63] \\
\hline ZEB1-AS1 & Upstream antisense RNA enhances ZEB1 expression. & Li et al. [90] \\
\hline Zeb2NAT & $\begin{array}{l}\text { Prevents splicing of the Zeb2 5'-UTR, increases Zeb2 and } \\
\text { downregulates E-cadherin. }\end{array}$ & Zhuang et al. [91] \\
\hline 91H & H19 antisense. Associated with H19 ICR methylation. & $\begin{array}{l}\text { Deng et al. [92] } \\
\text { Gao et al. [93] }\end{array}$ \\
\hline
\end{tabular}

Abbreviations: AOC4P, amine oxidase, copper containing 4, pseudogene; BANCR, BRAF-activated non-protein coding RNA; EMT, epithelial-mesenchymal transition; HOTAIR, HOX transcript antisense RNA; HULC, highly up-regulated in liver cancer; lncRNA, long noncoding RNA; MALAT-1, metastasis-associated lung adenocarcinoma transcript 1; Sox2, SRY (sex determining region Y)-box 2; TGF- $\beta$, transforming growth factor beta; ZEB1/2, zinc-finger E-box-binding homeobox $1 / 2$.

B1 (HMGB1), which enhances tumor cell motility and suppresses apoptosis [43]. The miR-200 family and the miR-183 96 182 cluster which are co-repressed in lung cancer inhibit EMT and metastasis by inducing forkhead box F2 (Foxf2), which correlates with ZEB1, represses E-cadherin and forms a double-negative feedback loop with the miR-200 family [44]. Though double-negative feedback loop between the miR-200 family and ZEB1/2 remains to be the most widely existed in many types of cancer $[45,46]$, it has also been applied in many other miRNAs such as miR-203 and miR-145. In breast cancer, Snail2 reduces expression of miR-203, while ectopic expression of miR-203 directly represses Snail2. The Snail2 and miR-203 regulatory loop is in concert with miR-200 and ZEB1/2, forming a feed-forward loop to regulate EMT and gene expression [47]. Similarly, the mutual control of miR-145 and ZEB2 contributes to prostate cancer progression and metastasis, wherein ZEB2 directly represses the transcription of miR-145, which in turn represses ZEB2 [48]. These reciprocal feedback loops may explain the reversibility of EMT and MET through an imbalanced expression of miRNAs and EMT transcription factors [49].

In addition to forming feedback loops, miRNAs can directly target transcription factors or signaling pathways of EMT. MiR-106b inhibits EMT and metastasis of endometrial cancer in vitro by directly downregulating Twist1 mRNA at the 3'UTR [50]. Reduced expression of
miR-145 promotes lung cancer cell EMT and metastasis via targeting octamer-binding transcription factor 4 (Oct4) mediated Wnt/ $\beta$-catenin signaling pathway [51]. Additionally, miRNAs also affect the integrity of the epithelial and mesenchymal architecture, thus regulating EMT. In gastric cancer cells, miR-30a directly targets the 3'UTR of vimentin, inhibits its protein level, thus decreasing EMT and cell invasion [52]. The expression of miR-30a is increased by overexpression of a putative tumor suppressor, Runt-related transcription factor 3 (RUNX3) [53]. MiR-506 suppresses EMT and metastasis of ovarian cancer through the direct downregulation of two mesenchymal marker proteins, vimentin and N-cadherin in vitro and in vivo [54]. Another EMT-inhibiting miRNA is miR-138, which suppresses EMT in head and neck squamous cell carcinoma cell lines via three distinct pathways: (a) by regulating the expression of vimentin, (b) by targeting ZEB2, (c) by the epigenetic regulator enhancer of zeste homolog (EZH2) $[55,56]$. Except for the miRNAs mentioned above, many new scenes have taken on in this field. Stromal interaction molecule 1 (STIM1), an endoplasmic reticulum $\mathrm{Ca}^{2+}$ sensor, is regulated by a post-transcriptional regulatory mechanism mediated by a novel EMT-inhibiting miRNA named miR-185 in the metastasis cascade of colorectal cancer [57]. 
Table 2: EMT-related IncRNA-miRNA interactions identified to-date

\begin{tabular}{|c|c|c|c|c|}
\hline LncRNA & \begin{tabular}{|l|} 
MicroRNA \\
\end{tabular} & $\begin{array}{r}\text { Mechanisms of interaction } \\
\end{array}$ & \begin{tabular}{|r|} 
Cancer types \\
\end{tabular} & References \\
\hline \multirow{3}{*}{ MALAT-1 } & miR-217 & miR-217-triggered MALAT-1 decay & lung cancer & Lu et al. [101] \\
\hline & miR-9 & miR-9-triggered MALAT-1 decay & osteosarcoma & Fang et al. [102] \\
\hline & miR-1 & $\begin{array}{l}\text { reciprocal negative control between } \\
\text { MALAT-1 and miR-1 }\end{array}$ & breast cancer & Jin et al. [103] \\
\hline \multirow{2}{*}{ HOTAIR } & $\operatorname{miR}-7$ & $\begin{array}{l}\text { HOTAIR downregulates } \operatorname{miR}-7 \text { by } \\
\text { inhibiting HoxD10 }\end{array}$ & breast cancer & Zhang et al. [114] \\
\hline & miR-568 & $\begin{array}{l}\begin{array}{l}\text { HOTAIR downregulates } \\
\text { chromatin modification }\end{array} \\
\end{array}$ & breast cancer & Li et al. [115] \\
\hline IncRNA-ATB & miR-200s & lncRNA-ATB acts as sponge of miR-200s & $\begin{array}{l}\text { hepatocellular } \\
\text { gastric cancer }\end{array}$ & $\begin{array}{l}\text { Yuan et al. [104] } \\
\text { Saito et al. [105] }\end{array}$ \\
\hline \multirow{4}{*}{ H19 } & let-7 & H19 acts as sponge of let-7 & pancreatic cancer & Ma et al. [106] \\
\hline & $\begin{array}{l}\text { miR-138 miR- } \\
200 \mathrm{a}\end{array}$ & $\begin{array}{l}\text { H19 acts as sponge of miR-138 and miR- } \\
200 \mathrm{a}\end{array}$ & colorectal cancer & Liang et al. [107] \\
\hline & miR-141 & H19 acts as sponge of miR-141 & gastric cancer & Zhou et al. [108] \\
\hline & miR-675 & H19 generates miR-675 & prostate cancer & Zhu et al. [112] \\
\hline lincRNA-ROR & miR-205 & lincRNA-ROR acts as sponge of miR-205 & breast cancer & Hou et al. [109] \\
\hline ZFAS1 & $\operatorname{miR}-150$ & ZFAS1 acts as sponge of miR- 150 & $\begin{array}{l}\text { hepatocellular } \\
\text { carcinoma }\end{array}$ & Li et al. [110] \\
\hline UCA1 & $\operatorname{miR}-145$ & $\begin{array}{l}\text { reciprocal negative control between UCA1 } \\
\text { and miR-145 }\end{array}$ & bladder cancer & Xue et al. [111] \\
\hline
\end{tabular}

Abbreviations: EMT, epithelial-mesenchymal transition; HOTAIR, HOX transcript antisense RNA; HoxD10, homeobox D10; lncRNA, long noncoding RNA; MALAT-1, metastasis-associated lung adenocarcinoma transcript 1; miRNA, microRNA; UCA1, the urothelial cancer associated 1 .

\section{EMT-activating miRNAs}

Compared with those miRNAs that suppress the EMT process, numbers of EMT-promoting miRNAs are relatively low. MiR-10b, the first reported metastasisrelated miRNA, could trigger the EMT of laryngeal carcinoma by directly targeting E-cadherin mRNA [58, 59]. E-cadherin is also targeted by miR-9 and miR-23a. MiR-9, which is frequently overexpressed in esophageal squamous cell carcinoma, promotes metastasis by directly targeting E-cadherin and increasing $\beta$-catenin nuclear translocation, and subsequently inducing EMT [60]. Through TGF- $\beta /$ Smad pathway [61], MiR-23a directly targets E-cadherin, promoting the mesenchymal phenotype with increased cell migration and invasion [62]. MiR-197 acts as an inducer of EMT in pancreatic cancer cells by indirectly targeting E-cadherin and regulating its membrane localization and trafficking via p120 catenin, an E-cadherin interaction protein [63]. Moreover, EMTpromoting miR-25 has been shown to be activated by the $\mathrm{Wnt} / \beta$-catenin signaling pathway. Upregulation of miR25 can inhibit the Rho GDP dissociation inhibitor alpha (RhoGDI1), enhancing expression of Snail and exerting its pro-metastatic function in hepatocellular carcinoma [64]. TGF- $\beta 1$-induced miR-20a directly inhibits Smad7, thus enhancing the activity of $\beta$-catenin pathway and inducing EMT in gallbladder carcinoma [65]. Another refers to miR-93, which results in the attenuation of Smad-dependent TGF- $\beta$ signaling and the activation of
PI3K/Akt pathway by suppressing TGFBR2, promoting nasopharyngeal carcinoma cell uncontrolled metastasis and EMT-like process [66]. According to Lamouille's report, TGFBR2, also targeted by miR-302/miR-372 family and miR-106 family, plays a key role in regulating MET and maintaining the mesenchymal state [49]. In conclusion, these miRNAs profiles in the regulation of EMT/MET programs have developed gradually and become a tool to understand cancer metastasis (Figure. 2).

\section{LNCRNAS' CONTROL OF EPITHELIAL- MESENCHYMAL PLASTICITY}

Although the functional roles of miRNAs in cancer metastasis are now well established, comparatively less is known about the regulatory roles of lncRNAs and their relevance to human diseases $[67,68]$. Most of $\operatorname{lncRNAs}$ do not code for proteins, but interact with them $[69,70]$. They are regulated like that of coding RNAs, subjecting to transcriptional regulation or even splicing, processing at the 5' and 3' ends, and exporting to the cytoplasm [71, 72]. Unlike microRNAs acting mainly as post-transcriptional repressors, Functional lncRNAs influence EMT in cancer metastasis through regulating gene expression at various levels, including chromatin modification, transcriptional and post-transcriptional processing $[73,74]$.

As the first disease-related ncRNA, MALAT-1, induced by TGF- $\beta$ in cancer cells, promotes EMT by interacting with suppressor of zeste 12 (suz12), the subunit 
of polycomb repressive complex 2 (PRC2), then leading to E-cadherin downregulation [75, 76]. Suz12 functions as a histone $\mathrm{H} 3$ lysine 27 (H3K27) methyltransferase to bind E-cadherin promoter and suppress its expression in a PRC2-dependent way [77]. Besides chromatin modification, MALAT-1 also functions as transcription regulator through activating Wnt signaling pathway, which results in increasing of ZEB1, ZEB2, Snail2 and decreasing of E-cadherin in bladder cancer, or suppressing PI3K-AKT pathway and inhibiting EMT in breast cancer [78, 79]. Kan et al demonstrated that the expression of MALAT-1 can be enhanced by TADCderived CCL5 in tumor microenvironment, subsequently increasing Snail expression [80]. Additionally, Shen et al found that silencing MALAT-1 may induce MET in the highly invasive subline of brain metastasis lung cancer cells, though the underlying mechanisms were not fully understood [81]. There are other lncRNAs functioning by chromatin modification, such as HOTAIR and H19. Both of them have been reported to interact with enhancer of zeste homolog 2 (EZH2), which also functions as a H3K27 methyltransferase when part of PRC2, to epigenetically inhibit genes responsible for suppressing cancer development, and increase metastasis [82-85].

LncRNAs perform their functions by regulating transcription through a broad spectrum of mechanisms. Linc00617 stimulates EMT via activating the transcription of Sox 2 which promotes the oncogenic activity of breast cancer cells [86]. Wang demonstrated that lncRNA AOC4P inhibited EMT by binding vimentin and promoting its degradation in hepatocellular carcinoma [87]. Additionally, it was recently reported that some lncRNAs can be influenced by tumor microenvironment. An aberrant IL-6/STAT3/lncTCF7 signaling axis, in which IL-6 in tumor microenvironment induces lncTCF7 via activating STAT3, contributes to hapatocellular carcinoma cells aggressiveness through EMT induction [88]. Another example is a liver metastasis specific lncRNA, HULC, which can also be affected by liver micro-environment [89].

Furthermore, several lncRNAs can serve as antisense transcripts forming duplex with their corresponding mRNA counterparts to either induce or inhibit their translation, and thus influencing EMT. ZEB1AS1 can induce EMT through positively regulating ZEB1 expression [90]. Ectopic overexpression of ZEB2NAT, which was founded in bladder cancer recently, prevents splicing of the ZEB2 5'-UTR, increases the levels of Zeb2 protein, and consequently downregulates E-cadherin mRNA and protein [91]. Further examples of antisense transcripts include 91H, ARNL (CDKN2B-AS1), and HNF1A-AS1 [92, 93].

In conclusion, Table 1 lists several selected lncRNAs with established roles in the EMT process. These representative IncRNAs are selected to illustrate the diverse mechanisms in EMT (Table. 1).

\section{LNCRNA-MICRORNA INTERACTIONS' CONTROL OF EPITHELIAL- MESENCHYMAL PLASTICITY}

While the action of miRNAs and lncRNAs as controllers of EMT/MET in cancer metastasis has been discussed, a number of new findings over the past decade have begun to uncover the interactions between lncRNAs and miRNAs in this process [94, 95, 99]. In some cases, IncRNA stability will be reduced due to the interaction with specific miRNAs. In other cases, IncRNAs, also known as competing endogenous (ce)RNAs, can sequester miRNAs away from their target mRNAs by binding miRNAs, therefore antagonizing miRNAs [100]. LncRNAs can also compete with miRNAs by binding mRNAs. What's more, some lncRNAs can produce miRNAs, causing repression of target mRNAs. These studies suggested that interplay patterns between IncRNAs and miRNAs may have an impact on cancer development and progression, so it is necessary to further dig into these interactions in the biological process of cancer [95]. The IncRNA-miRNA interactions identified to-date are summarized in Table 2.

\section{miRNAs triggering IncRNAs to decay}

MiR-217, a tumor suppressor, can inhibit MALAT-1 through the Ago2-mediated pathway, and thus inhibit EMT by suppressing EZH2-mediated H3K27me3, upregulating E-cadherin and downregulating N-cadherin and vimentin in cigarette smoke extract (CSE)-induced malignant transformation of HBE cells [101]. Similarly, the recruitment of miR-9 by $17 \beta$-Estradiol also causes decreased stability of MALAT-1 in osteosarcoma cell MG63 , and inhibits migration and invasion [102].

\section{IncRNAs binding miRNAs to derepress mRNAs}

There are lncRNAs which harbor similar miRNA target sequences, acting as miRNA sponges and hence sequestering miRNAs away from mRNAs, thereby derepressing mRNAs. For example, MALAT-1, which has complementary base pairing with miR-1, upregulates Slug expression through inhibiting miR-1 expression, and thus promotes EMT in triple-negative breast cancer [103]. Another was reported for IncRNA-ATB, which upregulated ZEB1 and ZEB2 by competitively binding the miR-200 family, and then induced EMT and invasion in both hepatocellular carcinoma and gastric cancer [104, 105]. Ma proposed that $\mathrm{H} 19$ promoted pancreatic ductal adenocarcinoma (PDAC) cell invasion and migration at least partially through antagonizing let-7 and then leading to derepression of its target high mobility group protein A2 (HMGA2) [106]. Additionally, other researches show 
that $\mathrm{H} 19$ also can act as ceRNAs for miR-138, miR200a and miR-141 in different cancer types respectively. Liang demonstrated that H19 can antagonize functions of miR-138 and miR-200a and led to the derepression of their endogenous targets vimentin, ZEB1 and ZEB2, thus promoting EMT in colorectal cancer [107]. With regard to miR-141, Zhou was the first to demonstrate that H19 and miR-141 could compete with each other and affect their target genes in gastric cancer [108]. Other examples are involved in lincRNA-ROR, ZFAS1 and lncRNA-UCA1. These lncRNAs can act as ceRNAs and contribute to EMT and cancer metastasis [109-111].

\section{IncRNAs generating miRNAs}

LncRNAs are also processed to generate miRNAs. Zhu found that H19 could generate miR-675 which suppressed prostate cancer EMT and metastasis by downregulating transforming growth factor $\beta$ induced protein (TGFBI), an extracellular matrix protein involved in cancer1metastasis [112]. This process during which H19 generates miR-675, is repressed by stress-response RNA binding protein HuR in a Drosha-dependent manner and dynamically regulated in vivo [113]. In addition, IncRNA HOTAIR, which is highly expressed in metastatic breast cancers, accelerates the EMT-dependent metastasis of breast cancer by inhibiting miR-7 through HoxD10 inhibition [114]. HOTAIR also transcriptionally inhibits the expression of miR-568 by directly targeting NFAT5 that promotes EMT in breast cancer [115]. However, further investigations are warranted to elucidate the relationship between IncRNAs and miRNAs for better therapeutic strategies.

\section{SUMMARY AND FUTURE PERSPECTIVES}

LncRNAs and miRNAs regulate gene expression involved in epithelial-mesenchymal plasticity on all levels. Through this sophisticated and multi-layered influence on protein expression patterns, these noncoding RNAs affect cancer metastasis and prognosis. Here, we have summarized the examples of a newly-developing mechanism - crosstalk between lncRNA and miRNA, and its influence on cancer metastasis cascade.

This crosstalk points out a novel way to understand the RNA networks. For example, the way miRNAs reduce lncRNA stability as described before is not entirely unexpected, since lncRNAs resemble mRNAs in many aspects. But whether or not miRNAs also regulate the transcription or splicing of lncRNAs requires further study $[116,117]$. In addition, some lncRNAs have the ability of sequestering a handful of miRNAs as a ceRNA just like H19, and one miRNA can also control many genes, thus making this crosstalk more complicated [85]. Apart from the direct interactions mentioned before, there may exist some indirect actions. For example, lacking an mRNA specific target site, miRNA can transcriptionally repress mRNA through lowering the levels of a miRNA-related lncRNA. Another challenge to hamper the application of the crosstalk mechanism in clinic is which cellular conditions should exist for the network to work, since researches evidenced that the relative concentration of lncRNAs and miRNAs must be suitable for interaction [118, 119]. Moreover, EMT/MET, as a complex bidirectional process, seems difficult to target. Inhibiting EMT or blocking cancer cell invasion may be applicable in early stage carcinomas. But once cancer cells have disseminated from the primary site, inhibiting EMT may be counterproductive, since it is beneficial for MET [120]. So finding out the exact mechanism in the secondary site colonization is quite important.

In conclusion, lncRNA-miRNA crosstalk not only suggests the existence of a complex regulatory network in cancer, but also implies the possibility of cancer diagnosis and therapy using this panel of network. Though in its infancy, its ability to contribute to cancer metastasis is continually being validated.

\section{ACKNOWLEDGMENTS}

This work was supported by National Natural Science Foundation of China grants (Nos. 81361120399, $81272961,81372891,81572650$ and 81672672$)$, by the Fundamental Research Funds of the Central Universities of China (2015), and by State Key Laboratory of Oral Diseases Special Funded Projects (SKLOD201512).

\section{CONFLICTS OF INTEREST}

There are no conflicts of interest to disclose.

\section{REFERENCES}

1. Tsai JH, and Yang J. Epithelial-mesenchymal plasticity in carcinoma metastasis. Genes \& development. 2013; 27: 2192-206.

2. Hanahan D, and Weinberg RA. Hallmarks of Cancer: The Next Generation. Cell. 2011; 144: 646-74.

3. Gupta GP, and Massague J. Cancer metastasis: Building a framework. Cell. 2006; 127: 679-95.

4. Thiery JP, and Sleeman JP. Complex networks orchestrate epithelial-mesenchymal transitions. Nat Rev Mol Cell Biol. 2006; 7: 131-42.

5. Wang Y, Bu F, Royer C, Serres S, Larkin JR, Soto MS, Sibson NR, Salter V, Fritzsche F, Turnquist C, Koch S, Zak J, Zhong S, et al. ASPP2 controls epithelial plasticity and inhibits metastasis through $\beta$-catenin-dependent regulation of ZEB1. Nat Cell Biol. 2014; 16: 1092-104.

6. Morrison $\mathrm{CD}$, Parvani JG, and Schiemann WP. The relevance of the TGF- $\beta$ Paradox to EMT-MET programs. 
Cancer Lett. 2013; 341: 30-40.

7. Brabletz T. To differentiate or not--routes towards metastasis. Nat Rev Cancer. 2012; 12: 425-36.

8. Thiery JP, Acloque H, Huang RY, and Nieto MA. Epithelial-Mesenchymal Transitions in Development and Disease. Cell. 2009; 139: 871-90.

9. Kalluri R, and Weinberg RA. The basics of epithelialmesenchymal transition. J Clin Invest. 2009; 119: 1420-8.

10. Cursons J, Leuchowius KJ, Waltham M, TomaskovicCrook E, Foroutan M, Bracken CP, Redfern A, Crampin EJ, Street I, Davis MJ, and Thompson EW. Stimulus-dependent differences in signalling regulate epithelial-mesenchymal plasticity and change the effects of drugs in breast cancer cell lines. Cell Commu Signal. 2015; 13: 26.

11. Turley EA, Veiseh M, Radisky DC, and Bissell MJ. Mechanisms of disease: epithelial-mesenchymal transition-does cellular plasticity fuel neoplastic progression? Nat Clin Pract Oncol. 2008; 5: 280-90.

12. Mattick JS, and Makunin IV. Non-coding RNA. Hum Mol Genet. 2006; 15: 17-29.

13. Ling H, Fabbri M, and Calin GA. MicroRNAs and other non-coding RNAs as targets foranticancer drug development. Nat Rev Drug Discov. 2013; 12: 847-65.

14. Liz J, Portela A, Solar M, Gómez A, Ling H, Michlewski G, Calin GA, Guil S, and Esteller M. Regulation of pri-microRNA processing by a long noncoding RNA transcribed from an ultraconserved region. Mol Cell. 2014; 55: $138-47$.

15. Iyer MK, Niknafs YS, Malik R, Singhal U, Sahu A, Hosono Y, Barrette TR, Prensner JR, Evans JR, Zhao S, Poliakov A, Cao X, Dhanasekaran SM, et al. The landscape of long noncoding RNAs in the human transcriptome. Nat Genet. 2015; 47: 199-208.

16. Liz J, and EstellerM. LncRNAs and microRNAs with a role in cancer development. Biochim Biophys Acta. 2016; 1859: 169-76.

17. Nantajit D, Lin D, and Li JJ. The network of epithelialmesenchymal transition: potential new targets for tumor resistance. J cancer Res Clin Oncol. 2015; 141: 1697-713.

18. Diaz-Lopez A, Diaz-Martin J, Moreno-Bueno G, Cuevas EP, Santos V, Olmeda D, Portillo F, Palacios J, and Cano A. Zeb1 and Snail1 engage miR-200f transcriptional and epigenetic regulation during EMT. Int J Cancer. 2015; 136: E62-73.

19. Puisieux A, Brabletz T, and Caramel J. Oncogenic roles of EMT-inducing transcription factors. Nat Cell Biol. 2014; 16: 488-94.

20. Sun T, Zhao N, Zhao XL, Gu Q, Zhang SW, Che N, Wang $\mathrm{XH}, \mathrm{Du}$ J, Liu YX, and Sun BC. Expression and functional significance of Twist1 in hepatocellular carcinoma: its role in vasculogenic mimicry. Hepatology. 2010; 51: 545-56.

21. Ocaña $\mathrm{OH}$, Córcoles R, Fabra A, Moreno-Bueno G, Acloque H, Vega S, Barrallo-Gimeno A, Cano A, and Nieto MA. Metastatic colonization requires the repression of the epithelial-mesenchymal transition inducer Prrx1. Cancer Cell. 2012; 22: 709-24.

22. Brabletz T. EMT and MET in metastasis: where are the cancer stem cells? Cancer Cell. 2012; 22: 699-701.

23. Said NA, Simpson KJ, and Williams ED. Strategies and challenges for systematically mapping biologically significant molecular pathways regulating carcinoma epithelial-mesenchymal transition. Cells Tissues Organs. 2013; 197: 424-34.

24. Chang CC, Hsu WH, Wang CC, Chou CH, Kuo MY, Lin BR, Chen ST, Tai SK, Kuo ML, and Yang MH. Connective tissue growth factor activates pluripotency genes and mesenchymal-epithelial transition in head and neck cancer cells. Cancer Res. 2013; 73: 4147-57.

25. Tan EJ, Olsson AK, and Moustakas A. Reprogramming during epithelial to mesenchymal transition under the control of TGF $\beta$. Cell Adh Migr. 2015; 9: 233-46.

26. Moustakas A, and Heldin P. TGF $\beta$ and matrix-regulated epithelial to mesenchymal transition. Biochim Biophys Acta. 2014; 1840: 2621-34.

27. O’Connell MP, Marchbank K, Webster MR, Valiga AA, Kaur A, Vultur A, Li L, Herlyn M, Villanueva J, Liu Q, Yin $\mathrm{X}$, Widura S, Nelson J, et al. Hypoxia induces phenotypic plasticity and therapy resistance in melanoma via the tyrosine kinase receptors ROR1 and ROR2. Cancer Discov. 2013; 3: 1378-93.

28. Faurobert E, Bouin AP, and Albiges-Rizo C. Microenvironment, tumor cell plasticity, and cancer. Curr Opin Oncol. 2015; 27: 64-70.

29. Guo F, Kerrigan BCP, Yang D, Hu L, Shmulevich I, Sood AK, Xue F, and Zhang W. Post-transcriptional regulatory network of epithelial-to-mesenchymal and mesenchymalto-epithelial transitions. J Hematol Oncol. 2014 ;7: 19.

30. D'Amato NC, Howe EN, and Richer JK. MicroRNA regulation of epithelial plasticity in cancer. Cancer Lett. 2013; 341: 46-55.

31. Bouyssou JM, Manier S, Huynh D, Issa S, Roccaro AM, and Ghobrial IM. Regulation of microRNAs in cancer metastasis. Biochim Biophys Acta. 2014; 1845: 255-65.

32. Bullock MD, Sayan AE, Packham GK, and Mirnezami AH. MicroRNAs: critical regulators of epithelial to mesenchymal (EMT) and mesenchymal to epithelial transition (MET) in cancer progression. Biol Cell. 2012; 104: 3-12.

33. Zhang J, and Ma L. MicroRNA control of epithelialmesenchymal transition and metastasis. Cancer Metastasis Rev. 2012; 31: 653-62.

34. D'Amato NC, Howe EN, and Richer JK. MicroRNA regulation of epithelial plasticity in cancer. Cancer Lett. 2013; 341: 46-55.

35. Saitoh M. Epithelial-mesenchymal transition is regulated at post-transcriptional levels by transforming growth factorbeta signaling during tumor progression. Cancer Sci. 2015; 106: 481-8. 
36. Korpal M, and Kang Y. The emerging role of miR-200 family of microRNAs in epithelial-mesenchymal transition and cancer metastasis. RNA Biol. 2008; 5: 115-9.

37. Mongroo PS, and Rustgi AK. The role of the miR-200 family in epithelial-mesenchymal transition. Cancer Biol Ther. 2010; 10: 219-22.

38. Feng X, Wang Z, Fillmore R, and Xi Y. MiR-200, a new star miRNA in human cancer. Cancer Lett. 2014; 344: 16673.

39. Burk U, Schubert J, Wellner U, Schmalhofer O, Vincan E, Spaderna S, and Brabletz T. A reciprocal repression between ZEB1 and members of the miR-200 family promotes EMT and invasion in cancer cells. EMBO Rep. 2008; 9: 582-9.

40. Gregory PA, Bracken CP, Bert AG, and Goodall GJ. MicroRNAs as regulators of epithelial-mesenchymal transition. Cell Cycle. 2008; 7: 3112-8.

41. Park DH, Jeon HS, Lee SY, Choi YY, Lee HW, Yoon S, Lee JC, Yoon YS, Kim DS, Na MJ, Kwon SJ, Kim DS, Kang J, et al. MicroRNA-146a inhibits epithelial mesenchymal transition in non-small cell lung cancer by targeting insulin receptor substrate 2. Int J Oncol. 2015; 47: 1545-53.

42. Brabletz S, and Brabletz T. The ZEB/miR-200 feedback loop--a motor of cellular plasticity in development and cancer? EMBO Rep. 2010; 11: 670-7.

43. Chang BP, Wang DS, Xing JW, Yang SH, Chu Q, and Yu SY. miR-200c inhibits metastasis of breast cancer cells by targeting HMGB1. J Huazhong Univ Sci Technolog Med Sci. 2014; 34: 201-6.

44. Kundu ST, Byers LA, Peng DH, Roybal JD, Diao L, Wang J, Tong P, Creighton CJ, and Gibbons DL. The miR-200 family and the miR-183 96 182 cluster target Foxf2 to inhibit invasion and metastasis in lung cancers. Oncogene. 2015; 23: 71 .

45. Bai WD, Ye XM, Zhang MY, Zhu HY, Xi WJ, Huang X, Zhao J, Gu B, Zheng GX, Yang AG, and Jia LT. MiR-200c suppresses TGF-beta signaling and counteracts trastuzumab resistance and metastasis by targeting ZNF217 and ZEB1 in breast cancer. Int J Cancer. 2014; 135: 1356-68.

46. Sundararajan V, Gengenbacher N, Stemmler MP, Kleemann JA, Brabletz T, and Brabletz S. The ZEB1/miR-200c feedback loop regulates invasion via actin interacting proteins MYLK and TKS5. Oncotarget. 2015; 6: 27083-96. doi: 10.18632/oncotarget.4807.

47. Ding X, Park SI, McCauley LK, and Wang CY. Signaling between transforming growth factor $\beta$ (TGF- $\beta$ ) and transcription factor SNAI2 represses expression of microRNA miR-203 to promote epithelial-mesenchymal transition and tumor metastasis. J Biol Chem. 2013; 288: 10241-53.

48. Renjie W, and Haiqian L. MiR-132, miR-15a and miR-16 synergistically inhibit pituitary tumor cell proliferation, invasion and migration by targeting Sox5. Cancer Lett.
2015; 356: 568-78

49. Lamouille S, Subramanyam D, Blelloch R, and Derynck R. Regulation of epithelial-mesenchymal and mesenchymalepithelial transitions by microRNAs. Curr Opin Cell Biol. 2013; 25: 200-7.

50. Dong P, Kaneuchi M, Watari H, Sudo S, and Sakuragi N. MicroRNA-106b modulates epithelial-mesenchymal transition by targeting TWIST1 in invasive endometrial cancer cell lines. Mol Carcinog. 2014; 53: 349-59.

51. Ling DJ, Chen ZS, Zhang YD, Liao QD, Feng JX, Zhang XY, and Shi TS. MicroRNA-145 inhibits lung cancer cell metastasis. Mol Med Rep. 2015; 11: 3108-14.

52. Liu Z, Chen L, Zhang X, Xu X, Xing H, Zhang Y, Li W, Yu $\mathrm{H}$, Zeng J, and Jia J. RUNX3 regulates vimentin expression via miR-30a during epithelial-mesenchymal transition in gastric cancer cells. J Cell Mol Med. 2014; 18: 610-23.

53. Li QL, Ito K, Sakakura C, Fukamachi H, Inoue Ki, Chi XZ, Lee KY, Nomura S, Lee CW, Han SB, Kim HM, Kim WJ, Yamamoto H, et al. Causal relationship between the loss of RUNX3 expression and gastric cancer. Cell. 2002; 109: 113-24.

54. Sun Y, Hu L, Zheng H, Bagnoli M, Guo Y, Rupaimoole R, Rodriguez-Aguayo C, Lopez-Berestein G, Ji P, Chen K, Sood AK, Mezzanzanica D, Liu J, et al. MiR-506 inhibits multiple targets in the epithelial-to-mesenchymal transition network and is associated with good prognosis in epithelial ovarian cancer. J Pathol. 2015; 235: 25-36.

55. Liu X, Wang C, Chen Z, Jin Y, Wang Y, Kolokythas A, Dai Y, and Zhou X. MicroRNA-138 suppresses epithelialmesenchymal transition in squamous cell carcinoma cell lines. Biochem J. 2011; 440: 23-31.

56. Yamasaki T, Seki N, Yamada Y, Yoshino H, Hidaka H, Chiyomaru T, Nohata N, Kinoshita T, Nakagawa M, and Enokida H. Tumor suppressive microRNA138 contributes to cell migration and invasion through its targeting of vimentin in renal cell carcinoma. Int J Oncol. 2012; 41: 805-17.

57. Zhang Z, Liu X, Feng B, Liu N, Wu Q, Han Y, Nie Y, Wu K, Shi Y, and Fan D. STIM1, a direct target of microRNA-185, promotes tumor metastasis and is associated with poor prognosis in colorectal cancer. Oncogene. 2015; 34: 4808-20.

58. Song Q, Xu Y, Yang C, Chen Z, Jia C, Chen J, Zhang Y, Lai P, Fan X, Zhou X, Lin J, Li M, Ma W, et al. miR-483-5p promotes invasion and metastasis of lung adenocarcinoma by targeting RhoGDI1 and ALCAM. Cancer Res. 2014; 74: 3031-42.

59. Zhang L, Sun J, Wang B, Ren JC, Su W, and Zhang T. MicroRNA-10b Triggers the Epithelial-Mesenchymal Transition (EMT) of Laryngeal Carcinoma Hep-2 Cells by Directly Targeting the E-cadherin. Appl Biochem Biotechnol. 2015; 176: 33-44.

60. Song Y, Li J, Zhu Y, Dai Y, Zeng T, Liu L, Li J, Wang H, Qin Y, Zeng M, Guan XY, and Li Y. MicroRNA-9 
promotes tumor metastasis via repressing E-cadherin in esophageal squamous cell carcinoma. Oncotarget. 2014; 5: 11669-80. doi: 10.18632/oncotarget.2581.

61. Derynck R, and Zhang YE. Smad-dependent and Smadindependent pathways in TGF- $\beta$ family signaling. Nature. 2003; 425: 577-584.

62. Cao M, Seike M, Soeno C, Mizutani H, Kitamura K, Minegishi Y, Noro R, Yoshimura A, Cai L, and Gemma A. MiR-23a regulates TGF-beta-induced epithelialmesenchymal transition by targeting E-cadherin in lung cancer cells. Int J Oncol. 2012; 41: 869-75.

63. Hamada S, Satoh K, Miura S, Hirota M, Kanno A, Masamune A, Kikuta K, Kume K, Unno J, Egawa S, Motoi F, Unno M, and Shimosegawa T. miR-197 induces epithelial-mesenchymal transition in pancreatic cancer cells by targeting p120 catenin. J Cell Physiol. 2013; 228: 1255 63.

64. Wang C, Wang X, Su Z, Fei H, Liu X, and Pan Q. miR-25 promotes hepatocellular carcinoma cell growth, migration and invasion by inhibiting RhoGDI1. Oncotarget. 2015; 6: 36231-44. doi: 10.18632/oncotarget.4740.

65. Chang Y, Liu C, Yang J, Liu G, Feng F, Tang J, Hu L, Li L, Jiang F, Chen C, Wang R, Yang Y, Jiang X, et al. MiR20a triggers metastasis of gallbladder carcinoma. J Hepatol. 2013; 59: 518-27.

66. Lyu X, Fang W, Cai L, Zheng H, Ye Y, Zhang L, Li J, Peng H, Cho WC, Wang E, Marincola FM, Yao K, Cai H, et al. TGF $\beta R 2$ is a major target of miR-93 in nasopharyngeal carcinoma aggressiveness. Mol Cancer. 2014; 13: 51.

67. Tsai MC, Spitale RC, and Chang HY. Long intergenic noncoding RNAs: new links in cancer progression. Cancer Res. 2011; 71: 3-7.

68. Gutschner T, and Diederichs S. The hallmarks of cancer: a long non-coding RNA point of view. RNA Biol. 2012; 9: 703-19.

69. Li CH, and Chen Y. Targeting long non-coding RNAs in cancers: progress and prospects. Int J Biochem Cell Biol. 2013; 45: 1895-910.

70. Li W, and Kang Y. A new Lnc in metastasis: long noncoding RNA mediates the prometastatic functions of TGF- $\beta$. Cancer Cell. 2014; 25: 557-9.

71. Barski A, Cuddapah S, Cui K, Roh TY, Schones DE, Wang Z, Wei G, Chepelev I, and Zhao K. High-resolution profiling of histone methylations in the human genome. Cell. 2007; 129: 823-37.

72. Tuck AC, and Tollervey D. A transcriptome-wide atlas of RNP composition reveals diverse classes of mRNAs and IncRNAs. Cell. 2013; 154: 996-1009.

73. Li Y, Chen H, Pan T, Jiang C, Zhao Z, Wang Z, Zhang $\mathrm{J}, \mathrm{Xu}$ J, and Li X. LncRNA ontology: inferring lncRNA functions based on chromatin states and expression patterns. Oncotarget. 2015; 6: 39793-805. doi: 10.18632/ oncotarget.5794.

74. Lin Z, Hu Y, Lai S, Xue M, Lin J, Qian Y, Zhuo W, Chen S,
Si J, and Wang L. Long Noncoding RNA: its partners and their roles in cancer. Neoplasma. 2015; 62: 846-54.

75. Ji P, Diederichs S, Wang W, Böing S, Metzger R, Schneider PM, Tidow N, Brandt B, Buerger H, Bulk E, Thomas M, Berdel WE, Serve H, et al. MALAT-1, a novel noncoding RNA, and thymosin beta4 predict metastasis and survival in early-stage non-small cell lung cancer. Oncogene. 2003; 22: 8031-41.

76. Fan Y, Shen B, Tan M, Mu X, Qin Y, Zhang F, and Liu Y. TGF- $\beta$-induced upregulation of malat1 promotes bladder cancer metastasis by associating with suz12. Clin Cancer Res. 2014; 20: 1531-41.

77. Kaneko S, Li G, Son J, Xu CF, Margueron R, Neubert TA, and Reinberg D. Phosphorylation of the PRC2 component Ezh2 is cell cycle-regulated and up-regulates its binding to ncRNA. Genes Dev. 2010; 24: 2615-20.

78. Ying L, Chen Q, Wang Y, Zhou Z, Huang Y, and Qiu F. Upregulated MALAT-1 contributes to bladder cancer cell migration by inducing epithelial-to-mesenchymal transition. Mol Biosyst. 2012; 8: 2289-94.

79. Xu S, Sui S, Zhang J, Bai N, Shi Q, Zhang G, Gao S, You Z, Zhan C, Liu F, and Pang D. Downregulation of long noncoding RNA MALAT1 induces epithelial-tomesenchymal transition via the PI3K-AKT pathway in breast cancer. Int J Clin Exp Pathol. 2015; 8: 4881-91.

80. Kan JY, Wu DC, Yu FJ, Wu CY, Ho YW, Chiu YJ, Jian SF, Hung JY, Wang JY, and Kuo PL. Chemokine (C-C Motif) Ligand 5 is Involved in Tumor-Associated Dendritic CellMediated Colon Cancer Progression Through Non-Coding RNA MALAT-1. J Cell Physiol. 2015; 230: 1883-94.

81. Shen L, Chen L, Wang Y, Jiang X, Xia H, and Zhuang Z. Long noncoding RNA MALAT1 promotes brain metastasis by inducing epithelial-mesenchymal transition in lung cancer. J Neurooncol. 2015; 121: 101-8.

82. Qiu JJ, Lin YY, Ye LC, Ding JX, Feng WW, Jin HY, Zhang Y, Li Q, and Hua KQ. Overexpression of long noncoding RNA HOTAIR predicts poor patient prognosis and promotes tumor metastasis in epithelial ovarian cancer. Gynecol Oncol. 2014; 134: 121-8.

83. Wu ZH, Wang XL, Tang HM, Jiang T, Chen J, Lu S, Qiu GQ, Peng ZH, and Yan DW. Long non-coding RNA HOTAIR is a powerful predictor of metastasis and poor prognosis and is associated with epithelial-mesenchymal transition in colon cancer. Oncol Rep. 2014; 32: 395-402.

84. Kim HJ, Lee DW, Yim GW, Nam EJ, Kim S, Kim SW, and Kim YT. Long non-coding RNA HOTAIR is associated with human cervical cancer progression. Int J Oncol. 2015; 46: 521-30.

85. Matouk IJ, Halle D, Raveh E, Gilon M, Sorin V, and Hochberg A. The role of the oncofetal H19 lncRNA in tumor metastasis: orchestrating the EMT-MET decision. Oncotarget. 2015; 7:3748-65. doi: 10.18632/ oncotarget.6387.

86. Li H, Zhu L, Xu L, Qin K, Liu C, Yu Y, Su D, Wu K, 
and Sheng Y. Long noncoding RNA linc00617 exhibits oncogenic activity in breast cancer. Mol Carcinog. 2015; 24: 22338 .

87. Wang TH, Lin YS, Chen Y, Yeh CT, Huang YL, Hsieh TH, Shieh TM, Hsueh C, and Chen TC. Long non-coding RNA AOC4P suppresses hepatocellular carcinoma metastasis by enhancing vimentin degradation and inhibiting epithelialmesenchymal transition. Oncotarget. 2015; 6: 23342-57. doi: 10.18632/oncotarget.4344.

88. Wu J, Zhang J, Shen B, Yin K, Xu J, Gao W, and Zhang L. Long noncoding RNA lncTCF7, induced by IL-6/ STAT3 transactivation, promotes hepatocellular carcinoma aggressiveness through epithelial-mesenchymal transition. J Exp Clin Cancer Res. 2015; 34: 116.

89. Matouk IJ, Abbasi I, Hochberg A, Galun E, Dweik H, and Akkawi M. Highly up-regulated in liver cancer noncoding RNA is overexpressed in hepatic colorectal metastasis. Eur J Gastroenterol Hepatol. 2009; 21: 688-92.

90. Li T, Xie J, Shen C, Cheng D, Shi Y, Wu Z, Deng X, Chen H, Shen B, Peng C, Li H, Zhan Q, and Zhu Z. Upregulation of long noncoding RNA ZEB1-AS1 promotes tumor metastasis and predicts poor prognosis in hepatocellular carcinoma. Oncogene. 2015; 15: 223.

91. Zhuang J, Lu Q, Shen B, Huang X, Shen L, Zheng X, Huang R, Yan J, and Guo H. TGF $\beta 1$ secreted by cancer-associated fibroblasts induces epithelial-mesenchymal transition of bladder cancer cells through lncRNA-ZEB2NAT. Sci Rep. 2015; 5: 11924.

92. Deng Q, He B, Gao T, Pan Y, Sun H, Xu Y, Li R, Ying $\mathrm{H}$, Wang F, Liu X, Chen J, and Wang S. Up-regulation of $91 \mathrm{H}$ promotes tumor metastasis and predicts poor prognosis for patients with colorectal cancer. PLoS One. 2014; 9: e103022.

93. Gao T, He B, Pan Y, Xu Y, Li R, Deng Q, Sun H, and Wang S. Long non-coding RNA $91 \mathrm{H}$ contributes to the occurrence and progression of esophageal squamous cell carcinoma by inhibiting IGF2 expression. Mol Carcinog. 2015; 54: 359-67.

94. Yoon JH, Abdelmohsen K, and Gorospe M. Functional interactions among microRNAs and long noncoding RNAs. Semi Cell Dev Biol. 2014; 34: 9-14.

95. Liz J, and Esteller M. lncRNAs and microRNAs with a role in cancer development. Biochim Biophys Acta. 2015; 1859: 169-76.

96. Guo Q, Zhao Y, Chen J, Hu J, Wang S, Zhang D, and Sun Y. BRAF-activated long non-coding RNA contributes to colorectal cancer migration by inducing epithelialmesenchymal transition. Oncol Lett. 2014; 8: 869-75

97. Sun M, Liu XH, Wang KM, Nie FQ, Kong R, Yang JS, Xia R, Xu TP, Jin FY, Liu ZJ, Chen JF, Zhang EB, De $\mathrm{W}$, et al. Downregulation of BRAF activated non-coding RNA is associated with poor prognosis for non-small cell lung cancer and promotes metastasis by affecting epithelialmesenchymal transition. Mol Cancer. 2014; 13: 68.
98. Richards EJ, Zhang G, Li ZP, Permuth-Wey J, Challa S, Li Y, Kong W, Dan S, Bui MM, Coppola D, Mao WM, Sellers TA, and Cheng JQ. Long non-coding RNAs (LncRNA) regulated by transforming growth factor (TGF) $\beta$ : LncRNAhit-mediated TGF $\beta$-induced epithelial to mesenchymal transition in mammary epithelia. J Biol Chem. 2015; 290: 6857-67.

99. Paraskevopoulou MD, and Hatzigeorgiou AG. Analyzing MiRNA-LncRNA Interactions. Methods Mol Biol. 2016; 1402: 271-86.

100. Yang C, Wu D, Gao L, Liu X, Jin Y, Wang D, Wang T, and Li X. Competing endogenous RNA networks in human cancer: hypothesis, validation, and perspectives. Oncotarget. 2016; 7:13479-90. doi: 10.18632/oncotarget.7266.

101. Lu L, Luo F, Liu Y, Liu X, Shi L, Lu X, and Liu Q. Posttranscriptional silencing of the lncRNA MALAT1 by miR-217 inhibits the epithelial-mesenchymal transition via enhancer of zeste homolog 2 in the malignant transformation of HBE cells induced by cigarette smoke extract. Toxicol Appl Pharmacol. 2015; 289: 276-85.

102. Fang D, Yang H, Lin J, Teng Y, Jiang Y, Chen J, and Li Y. $17 \beta$-estradiol regulates cell proliferation, colony formation, migration, invasion and promotes apoptosis by upregulating miR-9 and thus degrades MALAT-1 in osteosarcoma cell MG-63 in an estrogen receptor-independent manner. Biochem Biophys Res Commun. 2015; 457: 500-6.

103. Jin C, Yan B, Lu Q, Lin Y, and Ma L. Reciprocal regulation of Hsa-miR-1 and long noncoding RNA MALAT1 promotes triple-negative breast cancer development. Tumour biology. 2015.

104. Yuan JH, Yang F, Wang F, Ma JZ, Guo YJ, Tao QF, Liu F, Pan W, Wang TT, Zhou CC, Wang SB, Wang YZ, Yang $\mathrm{Y}$, et al. A long noncoding RNA activated by TGF- $\beta$ promotes the invasion-metastasis cascade in hepatocellular carcinoma. Cancer Cell. 2014; 25: 666-81.

105. Saito T, Kurashige J, Nambara S, Komatsu H, Hirata H, Ueda M, Sakimura S, Uchi R, Takano Y, Shinden Y, Iguchi T, Eguchi H, Ehata S, et al. A Long Non-coding RNA Activated by Transforming Growth Factor- $\beta$ is an Independent Prognostic Marker of Gastric Cancer. Ann Surg Oncol. 2015; 22: 915-22.

106. Ma C, Nong K, Zhu H, Wang W, Huang X, Yuan Z, and $\mathrm{Ai}$ K. H19 promotes pancreatic cancer metastasis by derepressing let-7's suppression on its target HMGA2mediated EMT. Tumour Biol. 2014; 35: 9163-9.

107. Liang WC, Fu WM, Wong CW, Wang Y, Wang WM, Hu GX, Zhang L, Xiao LJ, Wan DC, Zhang JF, and Waye MM. The lncRNA H19 promotes epithelial to mesenchymal transition by functioning as miRNA sponges in colorectal cancer. Oncotarget. 2015; 6: 22513-25. doi: 10.18632/ oncotarget.4154.

108. Zhou X, Ye F, Yin C, Zhuang Y, Yue G, and Zhang G. The Interaction Between MiR-141 and lncRNA-H19 in Regulating Cell Proliferation and Migration in Gastric Cancer. Cell Physiol Biochem. 2015; 36: 1440-52. 
109. Hou P, Zhao Y, Li Z, Yao R, Ma M, Gao Y, Zhao L, Zhang Y, Huang B, and Lu J. LincRNA-ROR induces epithelialto-mesenchymal transition and contributes to breast cancer tumorigenesis and metastasis. Cell Death Dis. 2014; 5: e1287.

110. Li T, Xie J, Shen C, Cheng D, Shi Y, Wu Z, Deng X, Chen H, Shen B, Peng C, Li H, Zhan Q, and Zhu Z. Amplification of Long Noncoding RNA ZFAS1 Promotes Metastasis in Hepatocellular Carcinoma. Cancer Res. 2015; 75: 3181-91.

111. Xue M, Pang H, Li X, Li H, Pan J, and Chen W. Long noncoding RNA UCA1 promotes bladder cancer cell migration and invasion by way of the hsa-miR-145ZEB1/2-FSCN1 pathway. Cancer Sci. 2015; 6: 128-44.

112. Zhu M, Chen Q, Liu X, Sun Q, Zhao X, Deng R, Wang Y, Huang J, Xu M, Yan J, and Yu J. IncRNA H19/miR675 axis represses prostate cancer metastasis by targeting TGFBI. FEBS J. 2014; 281: 3766-75.

113. Keniry A, Oxley D, Monnier P, Kyba M, Dandolo L, Smits G, and Reik W. The H19 lincRNA is a developmental reservoir of miR-675 that suppresses growth and Ighlr. Nat Cell Biol. 2012; 14: 659-65.

114. Zhang H, Cai K, Wang J, Wang X, Cheng K, Shi F, Jiang L, Zhang Y, and Dou J. MiR-7, inhibited indirectly by lincRNA HOTAIR, directly inhibits SETDB1 and reverses the EMT of breast cancer stem cells by downregulating the STAT3 pathway. Stem Cells. 2014; 32: 2858-68.
115. Li JT, Wang LF, Zhao YL, Yang T, Li W, Zhao J, Yu F, Wang L, Meng YL, Liu NN, Zhu XS, Gao CF, Jia LT, et al. Nuclear factor of activated T cells 5 maintained by Hotair suppression of miR-568 upregulates S100 calcium binding protein A4 to promote breast cancer metastasis. Breast Cancer Res. 2014; 16: 454.

116. Guttman M, Russell P, Ingolia NT, Weissman JS, and Lander ES. Ribosome profiling provides evidence that large noncoding RNAs do not encode proteins. Cell. 2013; 154: 240-51.

117. vanHeesch S, van Iterson M, Jacobi J, Boymans S, Essers PB, de Bruijn E, Hao W, MacInnes AW, Cuppen E, and Simonis M. Extensive localization of long noncoding RNAs to the cytosol and mono- and poly-ribosomal complexes. Genome Biol. 2014; 15: R6.

118. Tay Y, Rinn J, and Pandolfi PP. The multilayered complexity of ceRNA crosstalk and competition. Nature. 2014; 505: 344-52.

119. Denzler R, Agarwal V, Stefano J, Bartel DP, and Stoffel M. Assessing the ceRNA hypothesis with quantitative measurements of miRNA and target abundance. Mol Cell. 2014; 54: 766-76.

120. Tsai JH, Donaher JL, Murphy DA, Chau S, and Yang J. Spatiotemporal regulation of epithelial-mesenchymal transition is essential for squamous cell carcinoma metastasis. Cancer Cell. 2012; 22: 725-36. 